\title{
Sistem Informasi Penjualan Kayu Kusen Berbasis Website
}

\author{
Minda Septiani ${ }^{1}$, Rizki Aulianita ${ }^{2}$, Verra Sofica ${ }^{3}$, Noor Hasan ${ }^{4}$ \\ Universitas Bina Sarana Informatika ${ }^{1,4}$, Universitas Nusa Mandiri ${ }^{2,3}$, \\ minda.mdt@bsi.ac.id ${ }^{1}$, rizki.rzk@nusamandiri.ac.id ${ }^{2}$, verra.vsc@nusamandiri.ac.id $^{3}$, \\ noor.nhs@bsi.ac.id ${ }^{4}$
}

\begin{abstract}
Abstrak - Website merupakan kumpulan halaman dalam suatu domain yang memuat tentang berbagai informasi agar dapat dibaca dan dilihat oleh pengguna internet. Dengan adanya website, banyak informasi yang dapat disebar luaskan agar sampai pada pengguna informasi. Dalam perkembangan teknologi saat ini, penyampaian informasi yang cepat dan tepat sangat dibutuhkan. Perusahaan lebih mudah menyebarluaskan informasi yang mereka jual kepada masyarakat luas. Dengan adanya internet, perusahaan lebih mudah untuk menyebar luaskan informasi sehingga masyarakat lebih mudah untuk menerimanya. Dengan adanya teknologi internet saat ini sangat memudahkan didalam bidang promosi. Pelanggan dapat mengakses informasi selama 24 jam penuh dan mudah dengan cara mengunjungi halaman web yang dikenal dengan istilah website. Website dibuat dengan tujuan agar mempermudahkan para pelanggan untuk melihat-lihat jenis dan tipe yang ada dengan keterangan yang sangat jelas. Dan juga, memudahkan pelanggan untuk memesan kusen tanpa harus datang langsung ke perusahaan untuk memesan. Seperti kusen yang sangat dibutuhkan dan banyak dicari oleh masyarakat untuk melengkapi bangunan atau rumah mereka.

Kata Kunci : Sistem Informasi Penjualan, Website, Promosi, Kayu Kusen
\end{abstract}

\begin{abstract}
Website is a collection of pages in a domain that contains various information so that it can be read and viewed by internet users. With the website, a lot of information can be disseminated to reach information users. In today's technological developments, the delivery of information quickly and precisely is needed. It is easier for companies to disseminate the information they sell to the wider community. With the internet, it is easier for companies to disseminate information so that it is easier for people to receive it. With the internet technology today is very easy in the field of promotion. Customers can access information 24 hours a day and easily by visiting a web page known as a website. The website was created with the aim of making it easier for customers to see the types and types that exist with very clear information. And also, making it easier for customers to order frames without having to come directly to the company to order. Such as frames that are needed and much sought after by the community to complement their buildings or houses.
\end{abstract}

Keywords: Sales Information System, Website, Promotion, Wood Frame

\section{PENDAHULUAN}

Informasi adalah data yang telah diproses sedemikian rupa, sehingga memiliki arti yang lebih bermanfaat bagi penggunanya (Andrianof, 2018). Perkembangan teknologi yang semakin pesat akan membuar pekerjaan semakin mudah dan maksimal.

Kayu merupakan bahan dasar pembuatan kusen yang menjadi struktur bangunan, mempunyai fungsi sebagai perekat antara dinding dengan pintu dan jendela. Bahan baku kayu yang digunakan juga harus dari kayu yang mempunyai kualitas tinggi. Dengan tingginya permintaan kebutuhan kusen, maka perusahan penjual kusen akan semakin banyak pesanan.

Promosi merupakan suatu bentuk komunikasi pemasaran yang bertujuan untuk menyebarkan atau memberikan informasi ataupun untuk mempengaruhi konsumen agar tertarik terhadap produk yang ditawarkan oleh penyedia jasa tersebut (Rohaeni, 2016).

Web merupakan aplikasi yang berisi tentang dokumen-dokumen multimedia (teks, gambar, suara, animasi, video) yang didalamnya menggunakan protocol http (Hypertext Transfer
Protocol) yang mana mengaksesnya menggunakan browser (Wibisono, 2015).

Web promosi dibuat agar bisa mempermudah konsumen dalam memilih dan melakukan pembelian. Web promosi memerlukan fasilitas untuk menyebarkan informasi. Agar dapat memudahkan konsumen memilih kusen sesuai dengan berbagai macam bentuk dan kebutuhan maka penulis merancang sebuah website promosi, dengan tujuan memudahkan konsumen berinteraksi dan bertukar informasi. Terdapat 2 macam website, yaitu website statis dimana bisa dikatakan isi jarang diubah karena langsung dimasukkan kedalam kode PHP dan website dinamis dimana isi dapat berubah karena proses input oleh admin.

Sistem informasi didefinisikan sebagai rangkaian komponen yang saling berhubungan yang mengumpulkan atau dapat memproses, menyimpan dan mendistribusikan informasi guna mendukung pengambilan keputusan dalam organisasi (Hernandhi et al., 2018).

Sementara itu, promosi dipandang sebagai arus informasi atau persuasi satu arah yang dibuat untuk mempengaruhi seseorang atau 
organisasi kepada tindakan yang menciptakan pertukaran dalam pemasaran (Anggara, 2017). Bahasa pemrograman yang digunakan adalah PHP yaitu bahasa script server-side yang didesain untuk pengembangan web (Madcoms, 2016), HTML (Hipertext Markup Language) merupakan bahasa terstruktur untuk menandai bagian-bagian dari sebuah halaman (Enterprise, 2016), CSS yang digunakan untuk menggambarkan semantik presentasi dari dokumen yang dituliskan dengan menggunakan markup language (Prasetyo et al., 2015) dan Javascript yang merupakan bahasa scripting yang populer diinternet dan dapat bekerja di sebagian browser populer seperti IE, Mozilla, dll (Kostman \& Sumaryana, 2018).

Struktur navigasi pada website digunakan sebagai gambaran isi dari situs web tersebut (Binanto, 2010). Struktur navigasi yang digunakan adaah struktur navigasi campuran dimana isi website dapat dilihat secara menyeluruh.

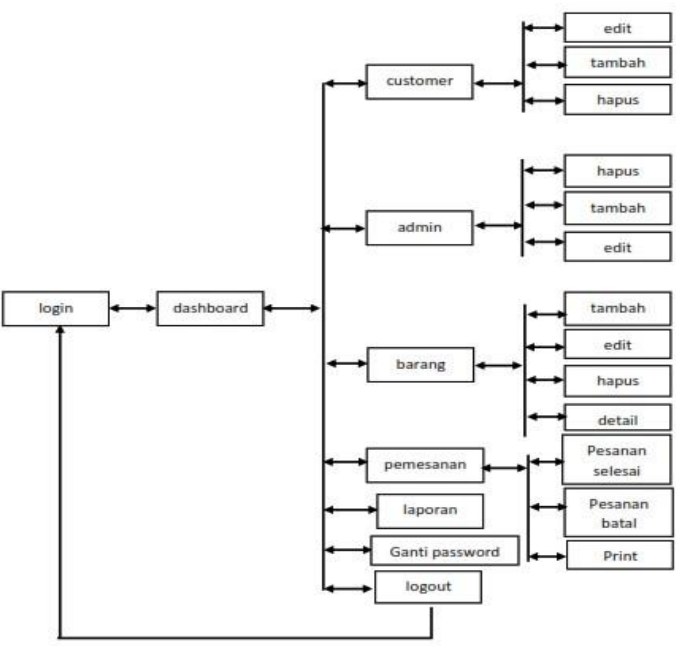

Sumber: Penelitian (2020)

Gambar 1. Struktur Navigasi Admin

Pada struktur navigasi admin gambar 1 dijelaskan apa saja yang bisa dilakukan oleh admin dalam program tersebut.

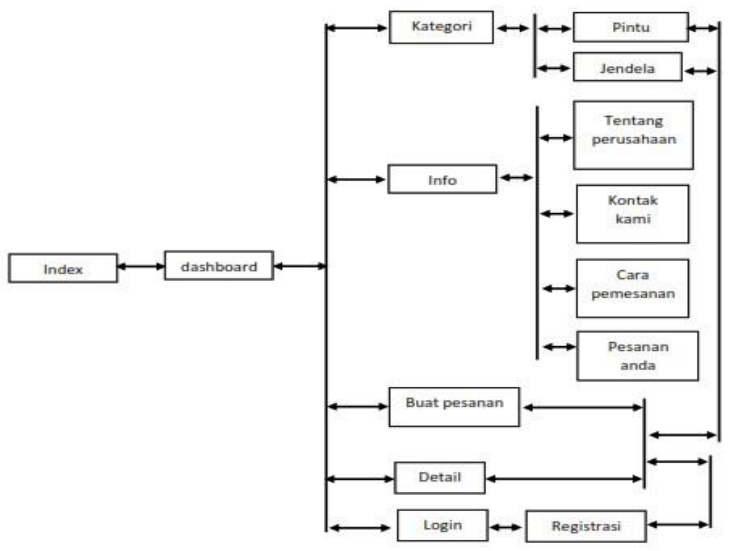

Sumber: Penelitian (2020)

Gambar 2. Struktur Navigasi Pengunjung
Pada struktur navigasi pengunjung gambar 2 dijelaskan apa saja tampilan yang bisa dilihat oleh pengunjung pada saat membuka website,

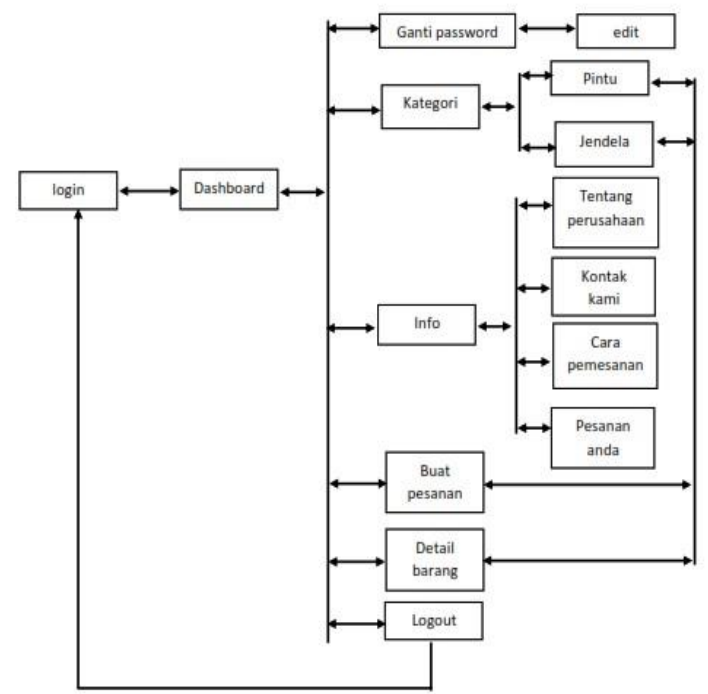

Sumber: Penelitian (2020)

Gambar 3. Struktur Navigasi Pelanggan Pada struktur navigasi pengunjung gambar 3 dijelaskan apa saja tampilan yang bisa dilihat oleh pelanggan pada saat membuka website, Analisis kebutuhan digunakan sebagai tahap awal untuk mempermudah pembuatan sistem, dengan adanya analisa diharapkan mampu menyesuaikan perangkat lunak yang sesuai dan berfungsi dengan baik untuk pengguna.

\section{METODOLOGI PENELITIAN}

Penulis menggunakan metodologi penelitian pengumpulan data dengan cara melakukan observasi dan studi pustaka. Dalam pembangunan websitenya menggunakan struktur navigasi campuran, dimana struktur navigasinya merupakan kombinasi antara struktur navigasi linear, nonlinear dan hierarchical. Metode pengembangan sistemnya menggunakan metode waterfall. Metode waterfall merupakan metode yang menyediakan alur hidup perangkat lunak secara terurut dimulai dari analisa kebutuhan perangkat lunak berdasarkan observasi dan identifikasi masalah pada objek penelitian. Desain berdasarkan perancangan struktur data, arsitektur perangkat lunak dan rancangan antar muka. Melakukan pembuatan kode program yang bertujuan agar sistem berfungsi sebagaimana yang diharapkan. Pengujian dilakukan untuk mengurangi kesalahan dan memastikan bahwa hasil sudah sesuai dengan yang diinginkan secara keseluruhan, dan yang terakhir pendukung, dimana program harus beradaptasi ketika sudah dikirimkan ke user.

\section{HASIL DAN PEMBAHASAN}

Pada penelitian ini aplikasi yang dihasilkan berbasis web, dimana admin dapat mengakses 
seluruh data yang ada pada sistem.

\section{A. Entity Relationship Diagram (ERD)} merupakan suatu model jaringan yang menggunakan susunan data yang dapat disimpan secara abstrak (Pertiwi, 2017)

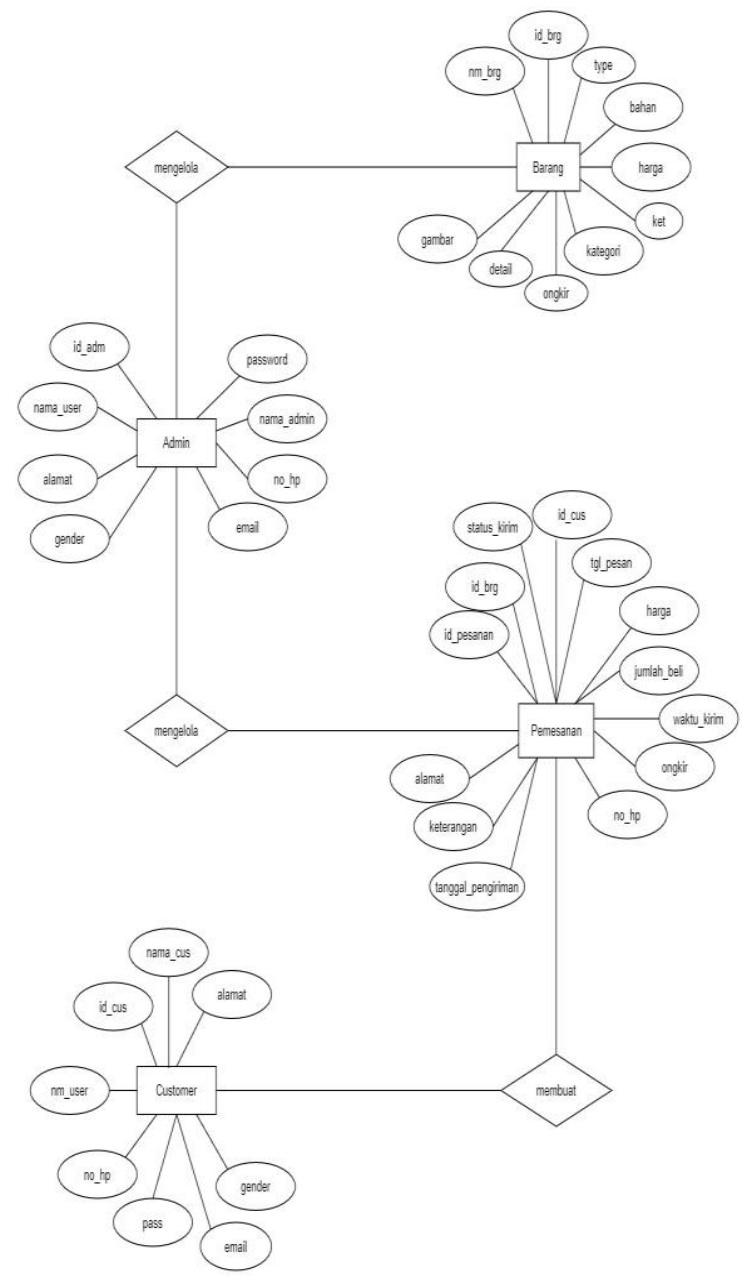

Sumber: Penelitian (2020)

Gambar 4. Entity Relationship Diagram (ERD)

Pada gambar 4 merupakan bentuk awal dalam melakukan perancangan basis data relational

B. Logical Record Structure (LRS) adalah model sistem yang mengikuti pola atau aturan permodelan dalam kaitan dengan konveksi ke LRS (Andika \& Buani, 2017)
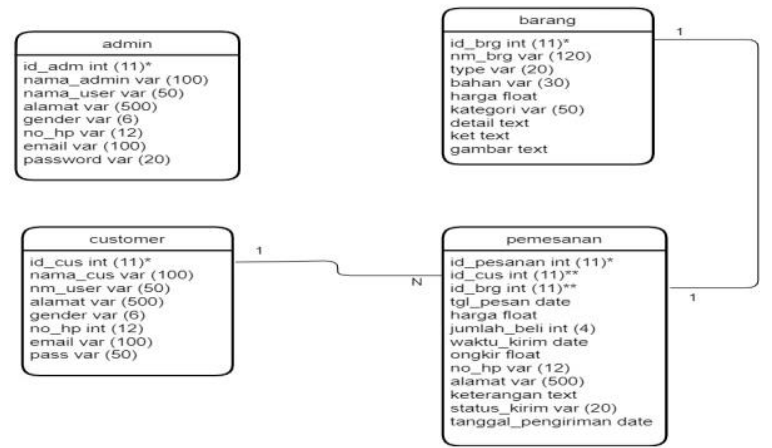

Sumber: Penelitian (2020)

Gambar 5. Logical Record Structure (LRS) Logical Record Structure (LRS) pada gambar 5 menjelaskan tentang struktur record pada table yang berelasi dan menentukan kardinalitas, jumlah tabel dan kunci pada masing-masing tabel.

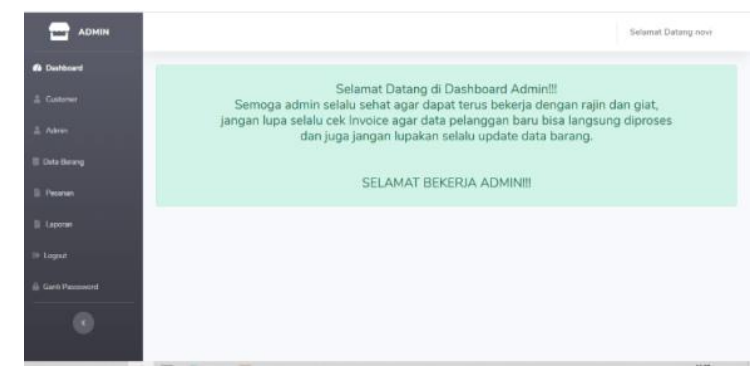

Sumber: Penelitian (2020)

Gambar 6. Tampilan Dashboard Admin Gambar 6 merupakan tampilan user interface dashboard admin berisi ucapan selamat datang dan menu yang bisa digunakan oleh admin

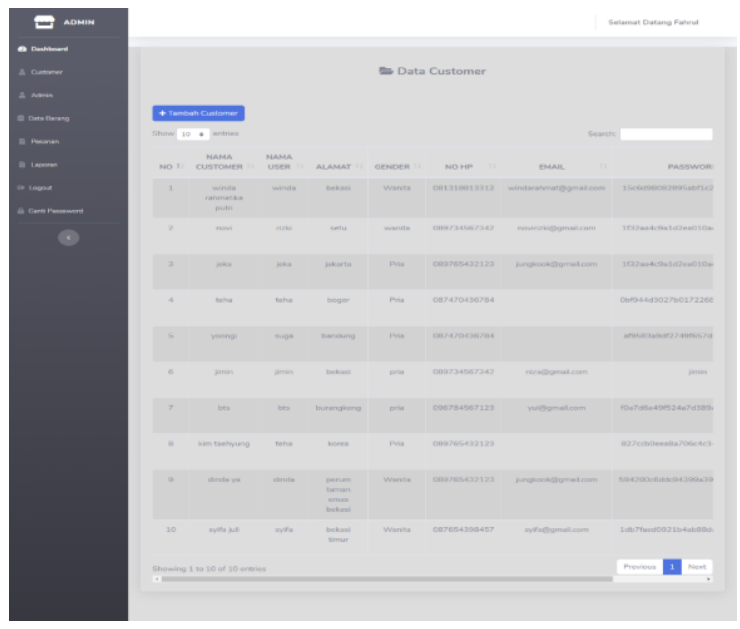

Sumber: Penelitian (2020)

Gambar 7. Tampilan Data Customer

Gambar 7 adalah tampilan data customer yang berisi data yang sudah diinputkan oleh customer pada saat login.
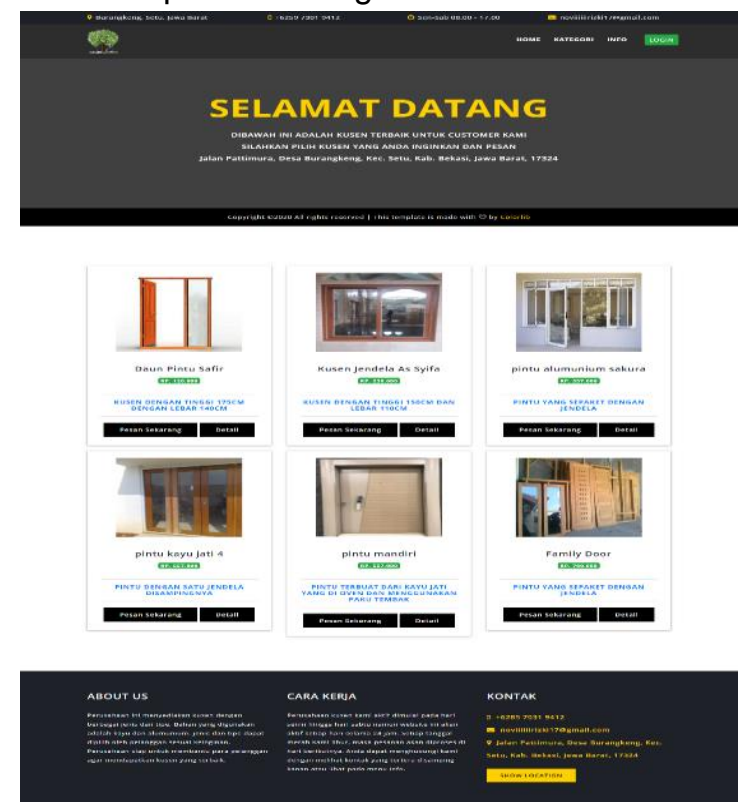

Sumber: Penelitian (2020)

Gambar 7. Tampilan Dashboard Pengunjung 
Tampilan dashboard pengunjung pada gambar 7 adalah tampilan yang dapat diakses tanpa harus login terlebih dahulu dan merupakan tampilan secara umum.

Tabel 1. Spesifikasi Data Barang

\begin{tabular}{clcccc}
\hline No & Elemen data & Akronim & Tipe & Size & Ket \\
\hline $\mathbf{1}$ & No & id_brg & Int & 11 & PK \\
$\mathbf{2}$ & Nama barang & nm_brg & Varchar & 120 & \\
$\mathbf{3}$ & Type & type & Varchar & 20 & \\
$\mathbf{4}$ & Nama Bahan & bahan & Varchar & 30 & \\
$\mathbf{5}$ & Harga & harga & Float & & \\
$\mathbf{6}$ & Kategori & kategori & Varchar & 50 & \\
$\mathbf{7}$ & Ongkos kirim & ongkir & Float & & \\
$\mathbf{8}$ & Detail & detail & Text & & \\
$\mathbf{9}$ & Keterangan & ket & Text & & \\
$\mathbf{1 0}$ & Gambar & gambar & Text & & \\
\hline
\end{tabular}

Sumber : Penelitian (2020)

Pada tabel 1 menunjukkan spesifikasi data barang yang terdiri dari 10 field dengan Primary Key adalah field id_brg (Nomor Id Barang)
Tabel 2. Spesifikasi File Customer

\begin{tabular}{clcccc}
\hline No & Elemen data & Akronim & Tipe & Size & Ket \\
\hline $\mathbf{1}$ & No & id_cus & Int & 11 & PK \\
$\mathbf{2}$ & Nama Customer & nama_cus & Varchar & 100 & \\
$\mathbf{3}$ & Nama User & nm_user & Varchar & 50 & \\
$\mathbf{4}$ & Alamat & alamat & Varchar & 500 & \\
$\mathbf{5}$ & Gender & gender & Varchar & 6 & \\
$\mathbf{6}$ & No hp & no_hp & Varchar & 12 & \\
$\mathbf{7}$ & Email & email & Varchar & 100 & \\
$\mathbf{8}$ & Password & pass & Varchar & 20 & \\
\hline
\end{tabular}

Sumber : Penelitian (2020)

Pada tabel 2 menunjukkan spesifikasi file customer yang terdiridari 8 field dengan Primary Key field id_cus (Nomor Customer)

Tabel 3. Blackbox Testing Halaman Login

\begin{tabular}{|c|c|c|c|c|c|}
\hline No & $\begin{array}{l}\text { Skenario } \\
\text { Pengujian }\end{array}$ & Test Case & Hal yang Diharapkan & $\begin{array}{c}\text { Hasil } \\
\text { Pengujian }\end{array}$ & Kesimpulan \\
\hline 1 & $\begin{array}{l}\text { Username dan } \\
\text { Password kosong, } \\
\text { atau diantara } \\
\text { keduanya kosong } \\
\text { dan klik login }\end{array}$ & $\begin{array}{l}\text { Username: (kosong) } \\
\text { Password: (kosong) } \\
\text { atau } \\
\text { Username: novi (benar) } \\
\text { Password: (kosong) } \\
\text { atau } \\
\text { Username: (kosong) } \\
\text { Password: } 123 \text { (benar) }\end{array}$ & $\begin{array}{l}\text { Sistem menolak untuk } \\
\text { mengakses halaman admin dan } \\
\text { menampilkan sebuah peringatan } \\
\text { "wajib diisi" }\end{array}$ & $\begin{array}{l}\text { Sesuai } \\
\text { harapan }\end{array}$ & Valid \\
\hline 2 & $\begin{array}{l}\text { Mengisi Username } \\
\text { benar dan } \\
\text { Password salah } \\
\text { atau sebaliknya } \\
\text { dan klik login }\end{array}$ & $\begin{array}{l}\text { Username: novi (benar) } \\
\text { Password: } 1234 \text { (salah) } \\
\text { Atau } \\
\text { Username: novi123 (salah) } \\
\text { Password: } 123 \text { (benar) }\end{array}$ & $\begin{array}{l}\text { Menampilkan peringatan } \\
\text { "username atau password anda } \\
\text { salah" }\end{array}$ & $\begin{array}{l}\text { Sesuai } \\
\text { harapan }\end{array}$ & Valid \\
\hline 3 & $\begin{array}{l}\text { Mengisi Username } \\
\text { dan Password } \\
\text { dengan salah dan } \\
\text { klik login }\end{array}$ & $\begin{array}{l}\text { Username: novi123 (salah) } \\
\text { Password: } 1234 \text { (salah) }\end{array}$ & $\begin{array}{l}\text { Sistem menolak untuk } \\
\text { mengakses halaman admin dan } \\
\text { menampilkan sebuah peringatan } \\
\text { "username atau password anda } \\
\text { salah" }\end{array}$ & $\begin{array}{l}\text { Sesuai } \\
\text { harapan }\end{array}$ & Valid \\
\hline 4 & $\begin{array}{l}\text { Mengisi Username } \\
\text { dan Password } \\
\text { dengan benar }\end{array}$ & $\begin{array}{l}\text { Username: novi (benar) } \\
\text { Password: } 123 \text { (benar) }\end{array}$ & $\begin{array}{l}\text { Sistem akan langsung } \\
\text { menampilkan halaman admin }\end{array}$ & $\begin{array}{l}\text { Sesuai } \\
\text { harapan }\end{array}$ & Valid \\
\hline
\end{tabular}

Sumber : Penelitian (2020)

\section{KESIMPULAN}

Website dibuat agar dapat mempermudah informasi. Dengan mengubah sistem yang sebelumnya manual menjadi sistem yang terkomputerisasi. Pelanggan juga mendapat kemudahan memilih barang yang diinginkan. Sehingga proses transaksi dapat berjalan lancar.

\section{REFERENSI}

Andika, N. ., \& Buani, D. C. . (2017). Perancangan Sistem Informasi Perpustakaan Studi Kasus: SMK YPKKesatuan Jakarta. Simnasiptek 2017, 1(1), 150-157. http://seminar.bsi.ac.id/simnasiptek/index. php/simnasiptek-2017/article/view/134

Andrianof, H. (2018). Rancang Bangun Sistem Informasi Promosi Dan Penjualan Pada Toko Ruminansia Berbasis Web. Jurnal
PTI.

https://core.ac.uk/download/pdf/22958685 4.pdf

Anggara, B. (2017). Perancangan Media Promosi PAUD Nirmala Sidoarjo Jawa Timur Melalui Media Brosur. Institut Bisnis Dan Informatika Stikom Surabaya. https://repository.dinamika.ac.id/id/eprint/2 432/1/COVER.pdf

Binanto, I. (2010). Multimedia Digital- Dasar Teori Pengembanganya.

Enterprise, J. (2016). Pengenalan HTML dan CSS.

Hernandhi, D. ., Astuti, E. ., \& Priambada, S. (2018). Desain Sistem Informasi Pemasaran Berbasis Website untuk Promosi (Studi Kasus pada Kedai Ayam Geprak \& Sambal Bawang Malang). Jurnal Administrasi Bisnis, 55(1), 1-10. http://administrasibisnis.studentjournal.ub. 
ac.id/index.php/jab/article/view/2235

Kostman, N., \& Sumaryana, Y. (2018). Aplikasi pemesanan tiket oto bus budiman berbasis online. Jurnal Manajemen Dan Teknik Informatika (JUMANTAKA), 1(1). http://jurnal.stmik-

dci.ac.id/index.php/jumantaka/article/view/ $275 / 0$

Madcoms. (2016). Pemrograman PHP Dan MySQL Untuk Pemula.

Pertiwi, F. . (2017). APLIKASI PENGOLAHAN DATA KONSTRUKSI PADA DINAS PENGELOLAAN SUMBER DAYA AIR PROVINSI SUMATERA SELATAN BERBASIS WEB. POLITEKNIK NEGERI SRIWIJAYA.

http://eprints.polsri.ac.id/4768/

Prasetyo, F. ., Satoto, K. ., \& Martono, K. .
(2015). Teknologi VRML untuk Media Promosi Mobil Berbasis Web. Jurnal Teknologi Dan Sistem Komputer, 3(1), 132-141.

https://jtsiskom.undip.ac.id/index.php/jtsisk om/article/view/11985

Rohaeni, H. (2016). Peranan Promosi Melalui Personal Selling Terhadap Volume Penjualan. Jurnal Ecodemica, 223-231. https://ejournal.bsi.ac.id/ejurnal/index.php/ ecodemica/article/view/802

Wibisono, G. (2015). Perancangan Website Sebagai Media Informasi dan Promosi Batik Khas Kabupaten Kulonprogo. Evolusi: Jurnal Sains Dan Manajemen, 3(2).

https://ejournal.bsi.ac.id/ejurnal/index.php/ evolusi/article/view/630 